\title{
Vital dye labelling demonstrates a sacral neural crest contribution to the enteric nervous system of chick and mouse embryos
}

\author{
GEORGE N. SERBEDZIJA ${ }^{1, *}$, SCOTT BURGAN ${ }^{2}$, SCOTT E. FRASER ${ }^{2}$ and MARIANNE BRONNER- \\ FRASER $^{1}$ \\ ${ }^{1}$ Developmental Biology Center, Department of Developmental and Cell Biology, ${ }^{2}$ Department of Physiology and Biophysics, University of \\ California, Irvine, CA 92717, USA \\ * Author for correspondence
}

\begin{abstract}
Summary
We have used the vital dye, DiI, to analyze the contribution of sacral neural crest cells to the enteric nervous system in chick and mouse embryos. In order to label premigratory sacral neural crest cells selectively, DiI was injected into the lumen of the neural tube at the level of the hindlimb. In chick embryos, DiI injections made prior to stage 19 resulted in labelled cells in the gut, which had emerged from the neural tube adjacent to somites 29-37. In mouse embryos, neural crest cells emigrated from the sacral neural tube between E9 and E9.5. In both chick and mouse embryos, DiI-labelled cells were observed in the rostral half of the somitic sclerotome, around the dorsal aorta, in the mesentery surrounding the gut, as well as within the epithelium of the gut. Mouse embryos, however, contained consistently fewer labelled cells than chick embryos. Dil-
\end{abstract}

labelled cells first were observed in the rostral and dorsal portion of the gut. Paralleling the maturation of the embryo, there was a rostral-to-caudal sequence in which neural crest cells populated the gut at the sacral level. In addition, neural crest cells appeared within the gut in a dorsal-to-ventral sequence, suggesting that the cells entered the gut dorsally and moved progressively ventrally. The present results resolve a long-standing discrepancy in the literature by demonstrating that sacral neural crest cells in both the chick and mouse contribute to the enteric nervous system in the postumbilical gut.

Key words: cell migration, gut, DiI, chick, mouse, enteric nervous system, neural crest.

\section{Introduction}

The enteric nervous system (ENS) comprises the parasympathetic ganglia of the gut, whose cells are derived from the neural crest (Yntema and Hammond, 1954; 1955; Andrew, 1971; Le Douarin, 1982; Rothman and Gershon, 1982; Baetge and Gershon, 1989; Epperlein et al. 1990). A major event in the development of the ENS is the colonization of the gut by neural crest cells. This process may shed light on the mechanisms controlling neural crest cell migration. Furthermore, it is medically important; improper migration of neural crest cells leads to birth defects such as colonic agangliogenesis (Hirschprung's disease), in which a portion of the bowel lacks enteric ganglia (Payette et al. 1988). In avian embryos, quail-chick chimerae have been used to establish that cells from the vagal region of the neural crest (arising from the neural tube adjacent to somites 1 to 7) colonize the bowel to form enteric ganglia (Le Douarin and Teillet, 1973, 1974). Quail-chick chimerae also suggest that sacral neural crest cells (arising from the neural tube adjacent to and caudal to somite 28) contribute to enteric ganglia in the postumbilical gut. However, this finding remains controversial. By examining the differentiation of morphologically identifiable neurons in explant cultures of chick embryo gut, Allan and Newgreen (1980) found no evidence for a contribution of the sacral neural crest to the gut. The explants were removed from different rostrocaudal levels of the gut, in the hope that all regions containing ENS precursors at the time of explantation would form neurons. Their results suggested that neural crest cells contribute to the ENS in a proximal-to-distal sequence, consistent with the colonization of the gut by vagal neural crest cells. Thus, they concluded that sacral neural crest cells are unlikely to contribute to the neurons of the gut.

These seemingly contradictory results have been difficult to resolve due to the different nature and inherent limitations of the approaches used to study this question. The quail-chick chimeric technique entails grafting tissues between different species. Because some quail cells may be more invasive than chick cells (Bellairs et al. 1981), it remains possible that donor 
quail cells behave differently after transplantation than host chick cells. However, the explant cultures of Allan and Newgreen were analyzed for the contribution of the neural crest to the gut by scoring morphologically identifiable 'neuroblasts'. The culture conditions may not have been permissive for the differentiation of all neuronal types; furthermore, such an assay would have missed any contribution to the non-neuronal components of the ENS by the sacral neural crest.

The use of the monoclonal antibody NC-1 (Vincent and Thiery, 1984) offers an independent means to evaluate the contribution to the enteric nervous system. In avian embryos, Pomeranz and Gershon (1990) identified a stream of NC-1-positive cells, which extended from the sacral neural tube to the level of the gut (Pomeranz and Gershon, 1990). Some of these NC1-positive cells within the gut assumed neuronal characteristics, suggesting that neural crest cells derived from the sacral level of the neural tube colonize the gut and contribute neurons to the developing ENS. Such immunohistochemical studies, however, only can provide an indirect assay of cell origin and movement. Because antibody labelling is performed on fixed sections of different embryos, it cannot be assured that the same population of cells are immunoreactive at different times or in different individuals. This is particularly problematic in the case of the NC-1 antibody, which recognizes a carbohydrate epitope that is found on several cell surface glycoproteins (Kruse et al. 1984) as well as glycolipids (Newgreen et al. 1990). This epitope is found on many, but not all neural crest cells (Teillet et al. 1987) and also is present on numerous other cell types. An additional complication is that the NC-1 antibody cannot distinguish between neural crest cells derived from sacral, vagal or other levels of the neuraxis. Thus, studies using the NC-1 antibody cannot resolve this controversy by establishing definitively a sacral neural crest cell contribution to the gut.

Recently, our laboratory has developed a technique for labelling premigratory neural crest cells by injecting a solution of the fluorescent carbocyanine dye, DiI, into the lumen of the neural tube (Serbedzija et al. 1989, 1990). DiI is lipid soluble and becomes incorporated into the plasma membrane of all cells that it contacts (Sims et al. 1974). It is passed to the progeny of the labelled cells but not to other cells (Honig and Hume, 1986). The dye does not appear to have any adverse affects on neuronal or neural crest cell development (Honig and Hume, 1986; Serbedzija et al. 1989, 1990), nor does the dye injection into living embryos itself appear to alter development (Serbedzija et al. 1989, 1990). Injection of DiI into the lumen of the neural tube offers a method to label premigratory neural crest cells directly. By controlling the time, site and size of injection into the sacral region, as well as the period of development postinjection, this technique provides a simple and non-deleterious way to study the temporal and spatial migratory patterns of neural crest cells in a variety of species without surgical disruption or possible culture artifacts. Here we use this approach to demonstrate that cells from the sacral neural crest populate the developing gut in chick and mouse embryos.

\section{Materials and methods}

\section{Preparation of eggs}

White Leghorn chicken embryos were incubated at $37^{\circ} \mathrm{C}$ until they reached stages 14 to 19 (Hamburger and Hamilton, 1951). The eggs were washed in $70 \%$ ethanol, a window was cut in the shell over the embryo and India ink (Pelikan, Hanover, FRG) was injected under the blastodisc to aid in visualization of the embryo. The vitelline membrane was deflected with a fine tungsten needle to allow access to the embryo. After dye injection, the egg was sealed with adhesive tape and returned to the incubator.

\section{Preparation of mouse embryos}

Embryos were obtained from CD-1 females that had been mated with BDF-1 males (Charles River) overnight. The presence of a vaginal plug the following morning indicated pregnancy, and the date that the plug was observed was designated as embryonic day zero (E0). Embryos were removed surgically from anesthetized mothers between late E9 and early E10 (18 to 33 somites), and placed in dissecting media consisting of $20 \%$ fetal bovine serum (Hyclone), $79 \%$ Dulbecco's Modified Eagle's medium (DMEM, Whittaker Bioproducts) and $1 \%$ penicillin-streptomycin L-glutamate mixture (GPS, Whittaker Bioproducts) at $37^{\circ} \mathrm{C}$. The embryos then were loosened and freed from the extraembryonic membranes, taking care not to damage the blood vessels within the membranes. Both the embryos and the membranes were left attached to the placenta for the entire culture period.

After dye injection, embryos were maintained, as described previously, in culture media consisting of $50 \%$ rat serum, $49 \%$ DMEM and $1 \%$ GPS (Serbedzija et al. 1990). The culture tubes were gassed with $95 \%$ oxygen $/ 5 \%$ carbon dioxide and rotated at 30 revs $\min ^{-1}$ at $37^{\circ} \mathrm{C}$. Embryos were cultured for either 12 or $24 \mathrm{~h}$ before fixation; those cultured for $24 \mathrm{~h}$ were gassed a second time after $12 \mathrm{~h}$ incubation.

\section{Microinjection of dye}

All injections were made by pressure with an $0.05 \%$ solution (weight/volume) of 1,1-dioctadecyl-3,3,3',3'-tetramethylindocarbo-cyanine perchlorate (Dil, Molecular Probes), made from an $0.5 \%$ stock solution in $100 \%$ ethanol diluted $1: 10$ in $0.3 \mathrm{M}$ sucrose. Prior to use, the DiI solution was heated to $37^{\circ} \mathrm{C}$ in order to prevent cold shock to the embryos and to help keep the Dil in solution. The injection micropipets were back-filled with the DiI solution, attached to a picospritzer (General Valve) and inserted into the lumen of the neural tube using a micromanipulator (Marzhauser). In most cases, the injections were made slightly rostral to the sacral region, with dye being expelled towards the caudal end of the embryo. Visual inspection of the embryo confirmed that the dye was confined to the sacral region of the neural tube, with no dye entering the truncal or vagal regions. Several embryos at various stages were injected such that the dye was expelled rostrally into the truncal and vagal regions. In these embryos, no DiI-labelled cells were observed in the postumbilical gut.

\section{Histology}

All embryos were fixed by immersion in $4 \%$ paraformaldehyde $/ 0.25 \%$ glutaraldehyde in $0.1 \mathrm{~m}$ phosphate buffer solution (PB) overnight at $4^{\circ} \mathrm{C}$. The embryos then were 
rinsed in $0.1 \mathrm{M}$ PB and soaked in a $15 \%$ sucrose solution for $12 \mathrm{~h}$ at $4{ }^{\circ} \mathrm{C}$. They were embedded in a $15 \%$ sucrose $/ 7.5 \%$ gelatin (Oxoid) solution for $2 \mathrm{~h}$ at $37^{\circ} \mathrm{C}$ and then rapidly frozen in liquid nitrogen. Serial sections were cut at a thickness of $25 \mu \mathrm{m}$ on a Zeiss Micron or AO Reichardt Histostat cryostat. Slides were mounted in Gel/Mount (Biomeda Corp.) and covered with glass coverslips. The sections were viewed on an epifluorescence microscope equipped with a light-intensifying camera (RCA SIT) and an image-processing system (Imaging Technologies Series 151), using the VidIm software package (developed by S. E. Fraser, G. Belford, J. Stollberg).

\section{Results}

Because DiI labels only those cells with which it comes into direct contact, injection of DiI into the neural tube lumen selectively labels the neural tube cells, including premigratory neural crest cells whose endfeet connect to the lumen (Serbedzija et al. 1989). By injecting small amounts of dye into the neural tube at the level of the hindlimb, it was possible to label sacral premigratory neural crest cells selectively without labelling cells at vagal or thoracic levels. The dye spread from the injection site caudally to the posterior neuropore. Avian embryos were injected with dye at stages ranging from 14 to 19 (Hamburger and Hamilton, 1951; 21-38 somite pairs) and were incubated in ovo for 24 to $48 \mathrm{~h}$. Mouse embryos were labelled at E9 to E10 (18-33 somite pairs) and incubated in vitro for 12 to $24 \mathrm{~h}$. Table 1 and Table 2 present the injection and fixation times for chick and mouse embryos, respectively, the total number of embryos examined at each stage and a summary of the results.

The majority of the observations were made in the region of the hindlimb (chick somite levels 26-32, mouse somite levels 23-28). In addition, we examined some of the embryos at the vagal and truncal levels to ensure that no neural crest cells other than those at sacral levels were labelled by our localized injections. In all of the chick and mouse embryos examined, DiIlabelled cells were not observed in the gut or other sites of neural crest cell localization at vagal or truncal levels of the neuraxis. When DiI was injected only into the trunk, no DiI-labelled cells were observed in the postumbilical gut.

\section{Chicken embryos}

\section{Injection at stage 14 (21-23 somites)}

Transverse sections through embryos labelled at the 21somite stage and incubated for $24 \mathrm{~h}$ contained streams of DiI-labelled cells which extended from the dorsal neural tube ventrally to the level of the dorsal aorta. Labelled cells were observed throughout the rostral half of each somitic sclerotome, except for a region around the notochord. This migratory pattern was similar to that observed at trunk levels of the neuraxis (somites 8-28; Serbedzija et al. 1989). Embryos injected at the 23-somite stage and incubated for $24 \mathrm{~h}$, until they reached stage 20 , contained streams of labelled cells as described above; in addition, a few labelled cells were observed extending into the dorsalmost portion of the dorsal mesentery of the gut (Fig. 1A,B). These labelled cells were observed in only the most rostral segment of the sacral gut (at the level of the rostral aspect of the hindlimb; 26-27 somite level).

Transverse sections through embryos injected at stage 14 and incubated for $36 \mathrm{~h}$ after injection, until they reached stage 21 , contained DiI-labelled cells throughout the sacral level of the gut. In the most rostral level of the sacral region, DiI-labelled cells were observed in both the dorsal and ventral portions of the gut mesenchyme, as well as within the dorsal portion of the gut epithelial layer. At the more caudal levels of the sacral region, DiI-labelled cells were observed only in the dorsal portion of the gut mesenchyme (Fig. 1C, D).

Table 1. Summary of experiments and results

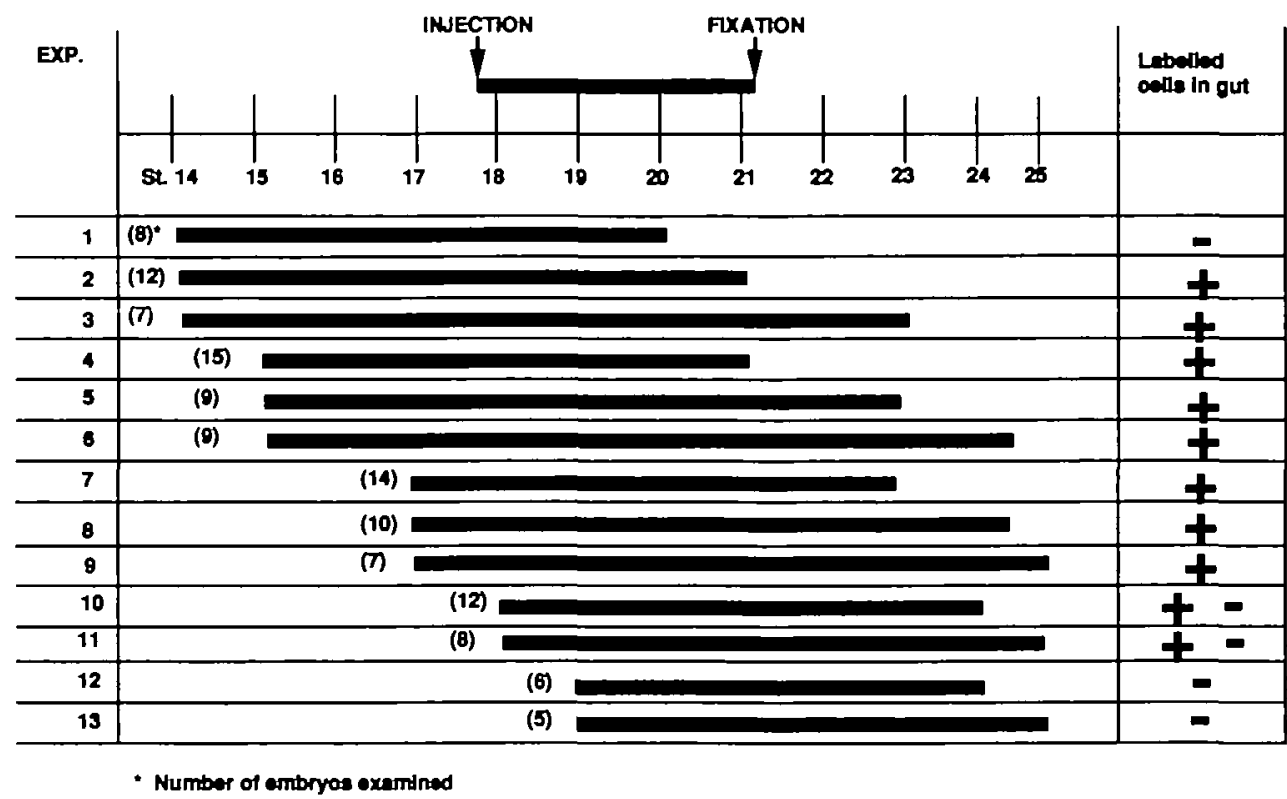


Table 2. Summary of mouse experiments and results

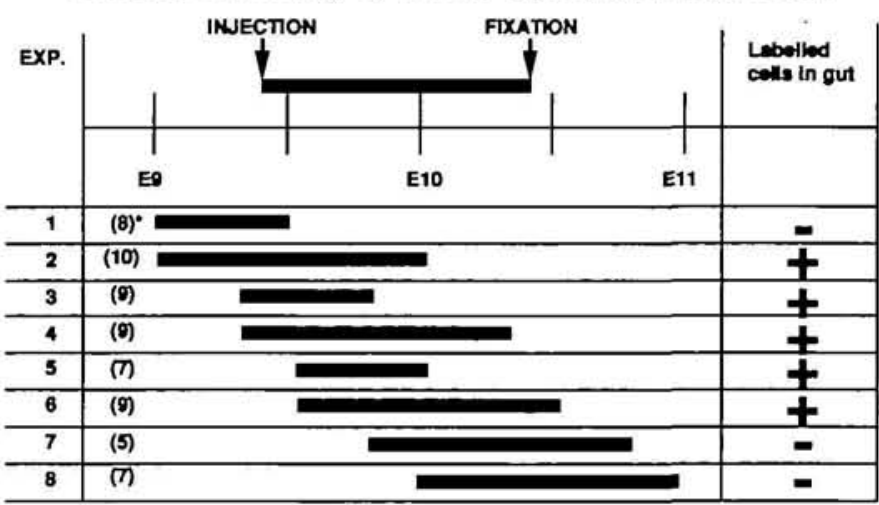

- Number of embryos examined
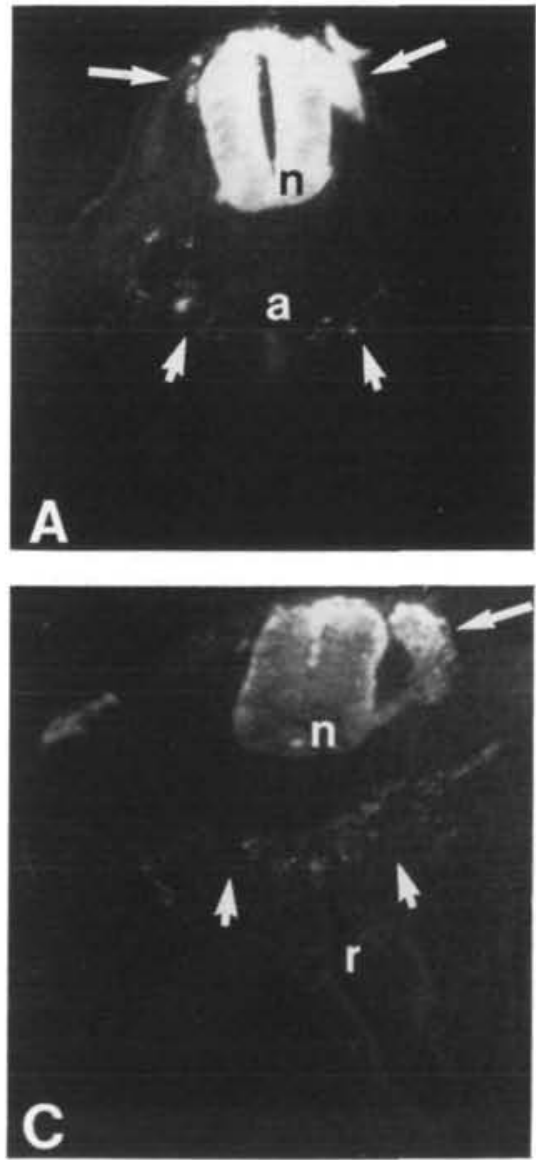

DiI-labelled cells also were observed in the regions of the condensing dorsal root and sympathetic ganglia.

Transverse sections through embryos incubated for $48 \mathrm{~h}$ (stage 23) contained DiI-labelled cells in similar locations to those described above. By this stage, DiIlabelled cells were found in the ventral portion of the gut mesenchyme throughout the sacral region (Fig. 2A,B).

\section{Injection at stages 15-16 (24-28 somites)}

Transverse sections through the sacral region of embryos injected at stages 15 and 16 and incubated for $24 \mathrm{~h}$, until they reached stage 21 , contained many DiIlabelled cells (approximately $50-100$ cells/section) in the dorsal portion of the gut. In the embryos injected at stage 15 (24-26 somite pairs), streams of labelled cells extended from the neural tube to the dorsal portion of the gut, where several individual DiI-labelled cells were
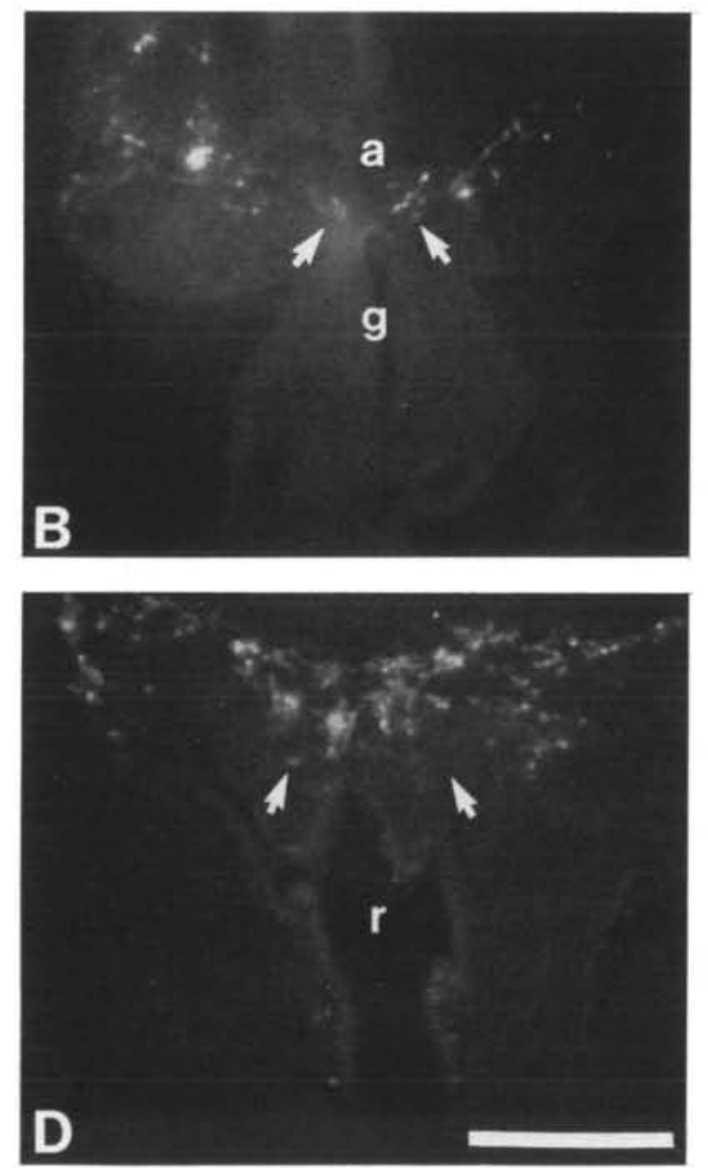

Fig. 1. Transverse sections through chick embryos labelled with DiI. (A) Section through the most rostral level of the sacral region (somite 26) of an embryo injected at stage 14 and incubated for $24 \mathrm{~h}$, until reaching stage 20. DiI-labelled cells extend from the dorsal portion of the neural tube ( $\mathrm{n}$; long arrows) to the level of the dorsal aorta (a; short arrows). (B) A higher magnification picture of the section shown in A. DiI-labelled cells are present between the dorsal aorta and the gut $(\mathrm{g})$, with a few cells present within the most dorsal portion of the gut mesenchyme (short arrows). (C) Section through the most caudal level of the sacral region (somite 32) of an embryo injected at stage 14 and incubated for $36 \mathrm{~h}$, until reaching stage 21 . DiI-labelled cells are present in the condensing dorsal root ganglia (long arrows) and sympathetic ganglia, as well as between the dorsal aorta and the gut. (D) A higher magnification picture of the section shown in C; DiI labelled cells are observed in the dorsal portion of the mesenchyme surrounding the rectum ( $r$; short arrows). (A,C: scale bar $=320 \mu \mathrm{m} ; \mathrm{B}, \mathrm{D}:$ scale $\mathrm{bar}=100 \mu \mathrm{m})$ 

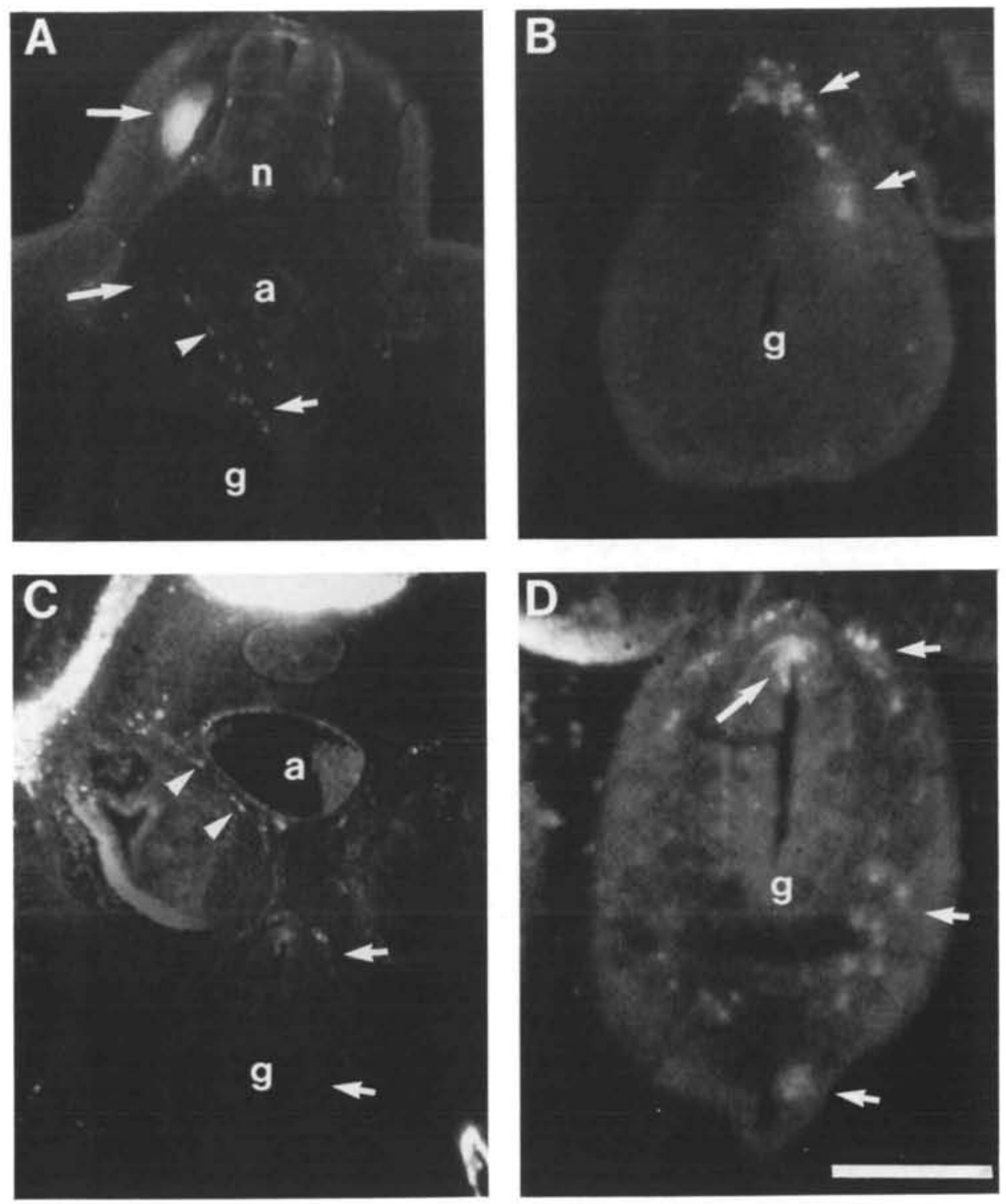

Fig. 2. Transverse sections through chick embryos labelled with DiI. (A) Section through an embryo injected at stage 14 and incubated for $48 \mathrm{~h}$, until reaching stage 23 . DiI-labelled cells are present in the gut mesenchyme (short arrow), in the dorsal root and sympathetic ganglia (long arrows), and in a stream of cells located ventral to dorsal aorta (arrowhead). (B) A higher magnification picture of the section shown in A.

Clusters of DiI-labelled cells are present in both the dorsal and middle portions of the gut mesenchyme (short arrows).

(C) Section through an embryo labelled at stage 16 and incubated for $36 \mathrm{~h}$, until reaching stage 22 . DiI-labelled cells are located throughout the dorsal and ventral portions of the gut mesenchyme (arrows), as well as in a stream extending from the sympathetic ganglia to the gut (arrowheads). (D) A higher magnification of the section shown in C; DiI-labelled cells appear throughout the gut mesenchyme (short arrows) and within the gut epithelium (long arrow). (A: scale bar $=320 \mu \mathrm{m} ; \mathrm{C}:$ scale bar $=200 \mu \mathrm{m} ; \mathrm{B}, \mathrm{D}$ : scale bar $=100 \mu \mathrm{m})$

recognizable (schematized in Fig. 4A). In sections through embryos injected at stage 16 (26-27 somite pairs), the streams of DiI-labelled cells extended further ventrally into the gut than in embryos injected at stage 15 , perhaps reflecting the fact that the host was slightly older at the time of fixation. A few individual Dil-labelled cells were identified in the middle and ventral portions of the gut.

In transverse sections through embryos injected at either stage 15 or 16 and incubated for $36 \mathrm{~h}$ after injection, until they reached stage 22 , DiI-labelled cells were found in the dorsal root ganglia and sympathetic ganglia, as well as throughout the mesenchyme of the gut. A few DiI-labelled cells (1-10 cells/embryo) were also observed in the gut epithelium (Fig. 2C,D; schematized in Fig. 4B). Embryos injected at stage 16 contained fewer labelled cells in the more rostral regions of the sacral gut than embryos injected at stage 15. This suggests a rostrocaudal order to the contri- bution of sacral neural crest cells to the gut, consistent with the rostrocaudal maturation of the embryo.

\section{Injection at stage 17 (29-32 somites)}

Transverse sections through the sacral region of embryos injected at stage 17 and incubated for 24 or $36 \mathrm{~h}$, until reaching stages 23 and 24 , respectively, contained DiI-labelled cells (approximately $25-50$ cells/ section) only in the more caudal levels of the gut. Labelled cells were located within the gut mesenchyme, as well as intercalated into the gut epithelium (similar to Fig. 2C,D; schematized in Fig. 4B). DiI-labelled cells also were present in dorsal root and sympathetic ganglia, in groups of cells around the dorsal aorta and underneath the ectoderm on the dorsolateral pathway. No DiI-labelled cells were found in the most rostral segments of the sacral gut, although labelled cells were present in other sites of neural crest cell localization as described above. 
Injection at stage 18 (33-36 somites)

Embryos injected at this stage and incubated for 24 or $36 \mathrm{~h}$ contained only limited numbers of labelled cells in the gut (less than 12), with the majority observed in the ventral portion of the caudal regions of the gut (schematized in Fig. 4C). These cells were more dimly labelled than those found in embryos injected at stage 17. Because this appears to be the last stage at which injection of dye into the neural tube yields labelled cells in the gut, it is likely that these dimly labelled cells emigrated from the neural tube shortly after injection of DiI, thereby limiting the time for dye incorporation. However, the distribution of DiI-labelled cells outside the gut was similar to that described above.

Injection at stage 19 (37-40 somites)

Embryos labelled at this stage contained no DiIlabelled cells in the gut. This suggests that all premigratory neural crest cells destined to contribute to the gut had already left the neural tube by stage 19 . DiIlabelled cells were present in the dorsal root and sympathetic ganglia and underneath the ectoderm along the dorsolateral pathway.

\section{Mouse embryos}

Injection at late E9 (18-20 somites)

Transverse sections through embryos injected at this stage and incubated for $12 \mathrm{~h}$ contained a few DiIlabelled cells in the rostral portion of the somitic sclerotome, suggesting that neural crest cells at this level were just beginning their migration. No labelled cells were present in the gut.

After $24 \mathrm{~h}$ of incubation, embryos injected at the 20 somite stage contained a few labelled cells in the dorsal portion of the gut in the sacral region of the embryo (Fig. 3A). In addition, labelled cells were seen in the rostral sclerotome and around the dorsal aorta, similar to the distribution observed in the trunk (Serbedzija et al. 1990).

\section{Injection at early E9.5 (21-23 somites)}

In transverse sections through the sacral region of embryos injected at early E9.5 and incubated for $12 \mathrm{~h}$, no labelled cells were observed in the gut. DiI-labelled cells were observed in the rostral sclerotome, at the level of the dorsal aorta and in the sympathetic ganglia.

Embryos incubated for $24 \mathrm{~h}$ contained DiI-labelled cells in the gut (approximately 25 cells/embryo). The majority of these cells were located in the dorsal portion of the gut, although a few labelled cells were observed more ventrally (Fig. 3B).

\section{Injection at mid E9.5 (24-26 somites)}

Embryos injected at 24- to 26-somite stage and incubated for $24 \mathrm{~h}$ contained many DiI-labelled cells (25-75 cells/embryo) in the sacral gut (Fig. 3C,D). Most of these labelled cells were located further ventrally than labelled cells in embryos injected at earlier stages. Labelled cells also were observed within the dorsal gut epithelium. There were no DiI-labelled cells observed in the gut rostral to the hindlimb bud.
DiI-labelled cells were observed in the region of the dorsal root and sympathetic ganglia, around the dorsal aorta, and along the dorsolateral pathway. The number of brightly labelled cells was reduced in comparison to the number observed in embryos injected at E9; the number of dimly labelled cells increased. This reduced dye content is consistent with the possibility that the DiI-labelled cells were proliferating rapidly; alternatively, these dimly labelled cells may have emigrated from the neural tube shortly after injection of DiI into the neural tube, thereby limiting the amount of dye that they could incorporate. The dimmer DiI-labelled cells tended to be further rostrad than the brightly labelled cells.

\section{Injection at late E9.5 (27-29 somites)}

Embryos injected at the 27- to 29-somite stage contained no DiI-labelled cells in the gut. DiI-labelled cells were observed in other neural crest derivatives, as described above.

\section{Dlscussion}

We have used a vital dye, DiI, to determine if cells from the sacral neural crest contribute to the development of the enteric nervous system (ENS) in chick and mouse embryos. By injecting DiI into the lumen of the neural tube at the level of the hindlimb, the premigratory sacral neural crest population was labelled selectively, without labelling vagal or truncal neural crest cells. In chick embryos, DiI-labelled cells were observed in the rostral half of the somitic sclerotome, around the dorsal aorta, in the mesentery surrounding the gut, as well as within the epithelium of the gut. The pattern of DiIlabelling was similar in the mouse embryo, although consistently fewer cells were observed. These results clearly support the conclusion of studies using chick/ quail chimerae (Le Douarin and Teillet, 1974) that the sacral neural crest contributes to the developing ENS.

By injecting DiI into chick embryos at a variety of stages, we were able to infer the times during which neural crest cells contributed to the enteric nervous system in sacral regions. The sacral neural crest cells that populate the gut emerge from the neural tube between stages 17 to 19 . This is supported by two observations: (1) DiI-labelled cells were found in the gut only for injections prior to stage 19, and (2) sacral neural crest cells were first observed external to the neural tube at stage 17 . We also were able to ascertain the pattern in which neural crest cells populate the gut. DiI-labelled cells first were observed in the rostral and dorsal portion of the gut at stage 21 . This coincides with the time when cells immunoreactive with the NC-1 antibody, which recognizes some neural crest cells, are evident in the avian gut at the sacral level (Pomeranz and Gershon, 1990). Paralleling the maturation of the embryo, there was a rostral-to-caudal sequence in which neural crest cells populated the gut at the sacral level. In addition, DiI-labelled cells appeared to populate the gut in a dorsal-to-ventral sequence, 

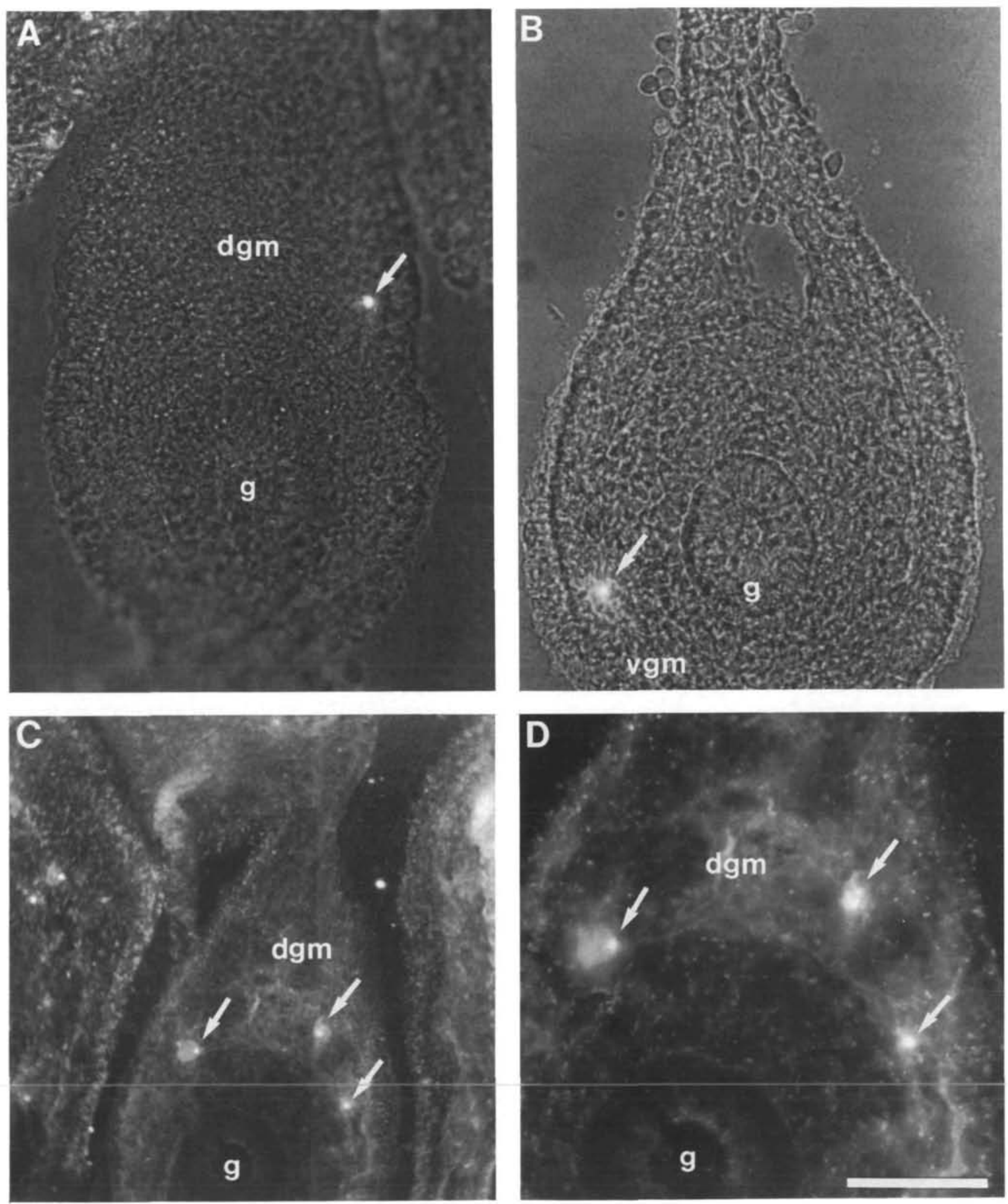

Fig. 3. Transverse sections through mouse embryos labelled with DiI. (A) Section through an embryo injected at the 20somite stage and incubated for $24 \mathrm{~h}$. A DiI- labelled cell is located in the dorsal portion of the gut mesenchyme (dgm; arrow). For orientation, the gut epithelium is labelled g. (B) Section through an embryo injected at the 22 -somite stage and incubated for $24 \mathrm{~h}$. A DiI-labelled cell can be observed in the ventral portion of the gut mesenchyme (vgm; arrow).

(C) Section through an embryo injected at the 24-somite stage and incubated for $24 \mathrm{~h}$. Three DiI-labelled cells are present in the dorsal portion of the gut mesenchyme (arrows). (D) A higher magnification of the section shown in C. (A,B,D: scale $\mathrm{bar}=50 \mu \mathrm{m} ; \mathrm{C}$ : scale $\mathrm{bar}=100 \mu \mathrm{m})$ 
A

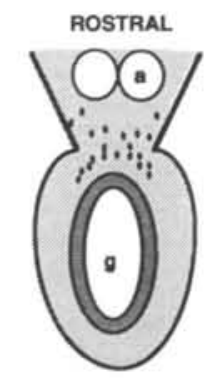

B

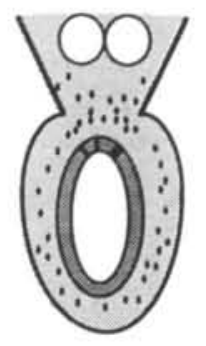

C

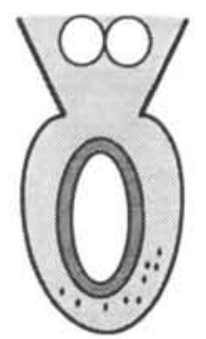

D

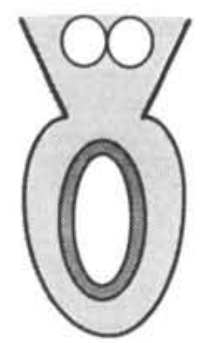

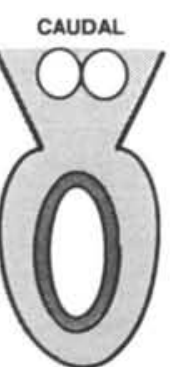
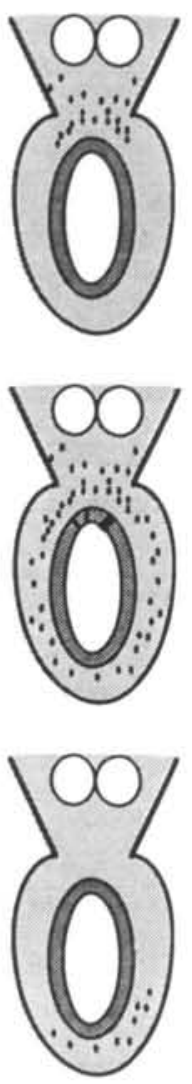

suggesting that the cells entered and colonized the gut dorsally, spreading progressively ventrally. Embryos fixed at early stages had DiI-labelled cells only in the dorsal portion of the gut, whereas embryos fixed at late stages contained labelled cells only in the ventral gut (schematized in Fig. 4). The finding that progressively later injections result in DiI-labelled cells in more caudal and ventral locations suggests that the gut is populated by neural crest cells in a rostrocaudal and dorsoventral sequence.

In the mouse, there were fewer DiI-labelled neural crest cells in the sacral gut than in chick embryos, although the overall distribution pattern was similar. By injecting embryos at various stages, we were able to infer that murine neural crest cells first emigrate from the sacral neural tube 2-4 somites rostral to the most recently formed somite in the mid-E9 embryo. By late E9.5 (27-29 somite pairs), those cells destined to populate the gut have already left the sacral neural crest. Similar to the chick embryo, there appeared to be a rostrocaudal and dorsoventral sequence of neural crest cell population of the mouse gut. There are two

Fig. 4. A schematic representation of the distribution of labelled cells in both the rostral and caudal portions of the gut ( $\mathrm{g}$; the dorsal aorta is indicated by an a) in chick embryos labelled with DiI at progressively later stages and incubated for $24 \mathrm{~h}$. While the observed pattern of cell distribution was similar for both the chick and the mouse, the number of DiI-labelled cells observed was far greater in the chick than in the mouse. (A) Embryos injected at stage 15 contained DiI-labelled cells only in the more rostral region of the sacral gut. These labelled cells were present only in the dorsal portion of the gut mesenchyme. (B) Embryos injected at stage 17 contained DiI-labelled cells throughout the rostral and caudal regions of the sacral gut. In the rostral region, DiI-labelled cells were present in both the dorsal and ventral portion of the gut mesenchyme, as well as within the dorsal gut epithelium. In the caudal region, labelled cells were present only in the dorsal portion of the gut mesenchyme. (C) Embryos injected at stage 18 contained DiI-labelled cells only in the ventral portion of the gut mesenchyme in the rostral region of the sacral gut, whereas the DiI-labelled cells were present in both the dorsal and ventral portion of the gut mesenchyme, as well as within the dorsal gut epithelium. (D) Embryos injected at stage 19 contained no DiI-labelled cells in the rostral regions of the sacral gut, and only a few labelled cells in the caudal regions. These DiI-labelled cells were present only in the ventral portion of the gut mesenchyme.

possible explanations for the reduced number of labelled cells observed in the mouse compared to the chick: (1) there may be fewer numbers of sacral neural crest cells in the enteric nervous system of the mouse, or (2) there may be equivalent numbers of sacral neural crest cells in both enteric nervous systems, but the mouse enteric nervous system may arise from fewer progenitor cells.

We were not able to determine the phenotypes of the DiI-labelled cells in our sections, because preservation of DiI requires fixation with paraformaldehyde and glutaraldehyde, which is incompatible with most antibody staining. Previous investigators have noted NC-1positive neuronal and non-neuronal cells in the sacral portion of the gut (Pomeranz and Gershon, 1990); however, the axial level of origin of these cells could not be ascertained. In addition to the labelled cells in the mesenchyme surrounding the gut, we observed labelled cells in the epithelium of the gut in both mouse and chick embryos. The fate of these cells is not clear, although they may represent neural crest cells intercalating into the epithelium. Previously, we noted a similar phenomenon, with neural crest cells invading the epithelium of the dermomyotome in the trunk of the chick embryo (Serbedzija et al. 1989) Unfortunately, we cannot follow the fate of these DiI-labelled cells for more than two days because the dye becomes progressively diluted with prolonged development. Furthermore, in the mouse, the short length of the culture period makes long-term identification of the labelled cells unfeasible.

In addition to enteric ganglia, sacral neural crest cells contribute to the dorsal root ganglia, sympathetic 
ganglia, and aortic plexuses at the level of the hindlimb. Furthermore, later emigrating DiI-labelled cells were observed underneath the epidermis, where pigment cells will differentiate. These derivatives and pathways of migration are similar to those of truncal neural crest cells. Thus, it appears that sacral neural crest cells give rise to the same derivatives as trunk neural crest cells, with an additional contribution to the enteric nervous system.

Both sacral and vagal neural crest cells invade the mesentery of the gut to contribute to the enteric nervous system whereas truncal neural crest cells do not normally enter the dorsal mesentery. Grafting experiments suggest that this differential ability to enter the gut is an inherent property of the neural crest cells derived from different axial levels. When a neural tube from the vagal region is transplanted in place of a trunk neural tube, the vagal neural crest cells not only migrate appropriately for their new environment (contributing to the dorsal root ganglia, sympathetic ganglia and adrenal medulla of the host), but also enter the gut (Le Douarin and Teillet, 1974; Smith et al. 1977). Because trunk neural crest cells do not normally enter this region, this suggests the presence of an inherent difference in neural crest cells from trunk and vagal levels. It has not yet been established if a similar situation exists for neural crest cells derived from sacral levels. However, its seems likely that the gut mesenchyme represents a non-permissive substrate for trunk neural crest cells, but a permissive one for vagal and sacral neural crest cells. Numerous extracellular matrix molecules, such as fibronectin, laminin, collagens, hyaluronate, etc. are distributed along neural crest migratory pathways (Pintar, 1978; Newgreen and Thiery, 1980; Krotoski et al. 1988; Perris et al. 1991a,b). In the lethal spotted mouse, a build-up of extracellular matrix components appears to restrict migration of neural crest cells into the post-umbilical bowel (Payette et al. 1988), suggesting that the excess or lack of some critical matrix component may be critical for this differential ability.

Our results support the idea that sacral neural crest cells contribute to the postumbilical gut, as originally proposed on the basis of quail-chick chimeric grafts (Le Douarin and Teillet, 1974). The negative result of Allan and Newgreen (1980) may have resulted from any of a number of factors. For example, sacral neural crest cells may contribute only non-neuronal cells to the gut, or they may give rise to neuronal types that are not readily detectable by the toluidine blue staining used in their study. The positive results presented here conclusively demonstrate that sacral neural crest cells contribute to the developing gut in both chick and mouse embryos.

\section{References}

Allan, I. J. And Newgreen, D. F. (1980). The origin and differentiation of enteric neurons of the intestine of the fowl embryo. Am. J. Anat. 157, 137-154.

ANDREw, A. (1971). The origin of intramural ganglia. IV. The origin of enteric ganglia: a critical review and discussion of the present stage of the problem. J. Anat. 108, 169-184.
Baetge, G. and Gershon, M. D. (1989). Transient catecholaminergic (TC) cells in the vagus nerves and bowel of fetal mice: relationship to the development of enteric neurons. Devl Biol. 132, 189-211.

Bellairs, R., Ireland, G. W., Sanders, E. J. and Stern, C. D (1981). The behavior of embryonic chick and quall tissues in culture. J. Embyol. exp. Morph. 61, 15-33.

Epperlein, H. H., Krotoski, D., Halfter, W. and Frey, A. (1990). Origin and distribution of enteric neurons in Xenopus. Anat. and Embryol. 182, 53-67.

Hamburger, V. and Hamiton, H. L. (1951). A series of normal stages in the development of chick embryos. J. Embryol. exp. Morph. 88, 49-92.

Honig, M. G. and Hume, R. I. (1986). Fluorescent carbocyanine dyes allow living neurons of identical origin to be studied in long-term cultures. J. Cell Biol. 103, 171-187.

Krotoski, D., Fraser, S. and Bronner-Fraser, M. (1988). Mapping of neural crest migration in Xenopus laevis embryos using inter- and intra-specific cell markers. Devl Biol. 127, 119-132.

Kruse, J., Mailhammer, R., Wernecke, H., Faissner, A., SOMmer, I., Goridis, C. AND Schachner, M. (1984). Neural cell adhesion molecules and myelin-associated glycoprotein share a common carbohydrate moiety recognized by monoclonal antibodies L2 and HNK-1. Nature 311, 153-155.

Le Douarin, N. M. (1982). 'The Neural Crest'. Cambridge: Cambridge Univ. Press.

Le Douarin, N. M. and Teillet, M. A. (1973). The migration of neural crest cells to the wall of the digestive tract in avian embryo. J. Embryol. exp. Morph. 30, 31-48.

Le Douarin, N. M. and Teillet, M. A. (1974). Experimental analysis of the migration and differentiation of neuroblasts of the autonomic nervous system and of neuroectodermal mesenchymal derivatives, using a biological cell marking technique. Devl Biol. 41, 162-184.

Newgreen, D. F., Powell, M. E. ANd Moser, B. (1990) Spatiotemperal changes in HNK-1 L2 glycoconjugates on avian embryo somite and neural crest cells. Devl Biol. 139, 100-120.

Newgreen, D. F. AND THIERY, J. P. (1980). Fibronectin in early avian embryos: synthesis and distribution along the migration pathways of neural crest. Cell Tissue Res. 211, 269-91.

Payette, R. F., Tennyson, V. M., Pomeranz, H. D., Pham, T. D., Rothman, T. P., Pomeranz, H. D. and Gershon, M. D. (1988). Accumulation of components of basal laminae: Association with the failure of neural crest cells to colonize the presumptive aganglionic bowel of $l s / l s$ mutant mice. Devl Biol. 137, 341-360.

Perris, R., Krotoski, D., Domingo, C., Lallier, T., Sorrell, J. M. and Bronner-Fraser, M. (1991a). Spatial and temporal changes in the distribution of proteoglycans during avian neural crest development. (In press, Development).

Perris, R., Krotoski, D. and Bronner-Fraser, M. (1991). Collagens in avian neural crest cell development: distribution in vivo and migration-promoting ability in vitro (submitted, Development)

PinTar, J. E. (1978). Distribution and synthesis of glycosaminoglycans during quail neural crest morphogenesis. Devl Biol. 67, 444-464.

Pomeranz, H. D. and Gershon, M. D. (1990). Colonization of the avian hindgut by cells derived from the sacral neural crest. Devl Biol. 137, 378-394.

Rothman, T. P. and Gershon, M. D. (1982). Phenotypic expression in the developing murine enteric nervous system. $J$. Neurosci. 2, 381-393.

Serbedzija, G. N., Bronner-Fraser, M. and Fraser, S. E. (1989). A vital dye analysis of the timing and pathways of avian neural crest cell migration. Development 106, 809-816.

Serbedzuna, G. N., Fraser, S. E. and Bronner-Fraser, M. (1990). Pathways of trunk neural crest cell migration in the mouse embryo as revealed by vital dye labelling. Development $108,605-612$.

Sims, P. J., WagGoner, A. S., Wary, L. H. and HoffMan, J. F (1974). Studies on the mechanisms by which cyanine dyes 
measure membrane potential in red blood cells in phosphatıdylcholine vesicles. Biochemistry 13, 3315-3330.

Smith, J., Cochard, P. H. and Le Douarin, N. M. (1977).

Development of choline acetyltransferase activities in enteric ganglia derived from presumptive adrenergic and cholinergic levels of the neural crest. Cell Diff. 6, 199-216.

Teillet, M. A., Kalcheim, K. AND Le Douarin, N. M. (1987).

Formation of dorsal root ganglia in the avian embryo:

Segmental origin and migratory behavior of neural crest progenitor cells. Devl Biol. 120, 329-347.

VINCENT, M. AND ThIERY, J. P. (1984). A cell surface marker for neural crest and placodal cells: further evolution in peripheral and central nervous system. Devl Biol. 103, 468-481.

YNTEMA, C. L. AND Hammond, W. S. (1954). The origin of intrinsic ganglia of trunk viscera from vagal neural crest in the chick embryo. J. comp. Neurol. 101, 515-541.

Yntema, C. L. AND Hammond, W. S. (1955). Experiments on the origin and development of sacral autonomic nerves in the chick embryo. J. exp. Zool. 129, 375-414.

(Accepted 15 January 1991) 